Carlos Hallet, S.J.

Profesor de la Universidad Católica del Norte

Antofagasta-Chile.

\title{
La teología de la luz de Guerrico de Igny
}

Guerrico, nacido entre 1070 y 1080 en Tournai, Bélgica, era canónigo de la catedral de su ciudad natal cuando conoció personalmente a san Bernardo. Por el año 1120 , hombre ya maduro y lleno de experiencia, se hizo monje en la abadía de Claraval, donde tuvo de connovicio al futuro Eugenio III. Cerca del año 1138 fue elegido segundo abad de la reciente fundación de Igny, en la diócesis de Reims.

Hombre físicamente débil y de poca salud, pero estudioso y famoso por su santidad y sus escritos, este "hijo predilecto" de san Bernardo nos ha dejado 54 sermones de un estilo muy elegante, pero a la vez claro y sencillo. Redactados para la alimentación espiritual de sus religiosos, nos revelan a un Guerrico tierno, suave y talentoso, que domina todas las técnicas del arte de escribir y hablar, que utiliza las aliteraciones y las inversiones y da a sus frases un ritmo perfecto. Tiene un extraordinario conocimiento de las Sagradas Escrituras, de los textos litúrgicos y de la patrística latina, en particular de las obras de Agustín y Bernardo, además de Ambrosio, Beda el Venerable, Benito, Casiano, Gregorio Magno, Jerónimo y León Magno y otros.

Sus textos, llenos de sabiduría y bondad, son una excelente muestra de la espiritualidad del Císter, la cual equilibra armoniosamente afectividad y racionalidad.

El abad más famoso de Igny falleció en 1157. Beatificado por el papa León XIII y celebrado el 19 de agosto, Guerrico de Igny es uno de los pilares de la primera generación de cistercienses junto con san Bernardo de Claraval y los bienaventurados Guillermo de Saint-Thierry y Elredo de Rievaulx.

\section{UNA TEOLOGÍA DE LA LUZ}

La teología espiritual del siglo XII y del Císter en particular ha sido una teología de la luz y de la afirmación más que de la tiniebla y de la negación. Guerrico es un destacado testigo de esa corriente. Su teología está diseminada en el conjunto de sus sermones, la de la luz aparece más extensamente en el Sermo secundus y el Sermo tertius de Epiphania y en el Sermo primus in Purificatione (1) (2).

(1) Seguimos la numeración de la Patrología Latina de Migne, t. 185. La colección Sources Chrétiennes ha publicado Guerric d'Igny. Sermons, introduction, texte critique, notes et traduction par J. MORSON, H. COSTELLO et P. DELSEILlE, 2 t., Cerf, Paris, 1970-1973.

(2) Sobre la teología de la luz se puede consultar el artículo Illumination en Dictionnaire de Spiritualité, Beauchesne, Paris, t. VII, 1975, cc. 1330-1367 y Lumière, ibid., t. IX, 1976, cc. 1142-1183. 
Una sistematización de su pensamiento hace resaltar cómo de Dios que es Luz procede nuestra iluminación, la cual culmina en una transformación del alma en la imagen del Creador.

\section{DIOS}

La teología de la luz de Guerrico arranca del título dado a Dios por la Carta de Santiago (1,17). Dios es el Padre de las luces ("Pater luminum") (58 D, 186 A), de quien nos viene todo don perfecto y todo regalo óptimo $(50 \mathrm{D})$ y en quien no hay ni cambio ni oscuridad $(211$ D). Es Él que nos ha llamado de las tinieblas a su luz admirable ( $1^{a}$ Pedro 2,9$)$. Ha hecho salir la luz de las tinieblas y la ha hecho brillar en nuestros corazones para que nuestra ciencia sea iluminada y podamos conocer la faz de Cristo. Conocerle a Él, el único Dios, y a su enviado Jesús, la luz verdadera, no es otra cosa que la vida eterna (cf. Juan 17, 3).

En esas pocas palabras, Guerrico nos da una de las claves de su teología: la luz verdadera es la vida eterna y es conocimiento. Ahora bien, este conocimiento procede de la fe. Por eso él pide ser conducido de fe en fe (cf. Romanos 1, 17), es decir de claridad en claridad, bajo la moción del Espíritu, para penetrar los tesoros de la luz más profundamente de día en día. Así, "la fe crecerá, la ciencia se enriquecerá y la caridad será más ferviente y más universal” (52 B-C).

Dios el Señor, es el Sol invisible, fuente y origen de la luz (53 C); es también el Padre cuya sabiduría somos incapaces de escudriñar, ya que ella está escondida en el misterio (cf. $1^{a}$ Corintios 2, 7) y en la majestad de su santuario, majestad maravillosa cuya gloria es aplastante $(53 \mathrm{D}-54 \mathrm{~B})$.

Dios es el Ser que habita una luz inaccesible $\left(1^{a}\right.$ Timoteo 6, 16) $(185$ B; 211 C), pero, además, es el gran Paterfamilias (55 A), el iluminador de todas las naciones (56 C). Su luz, simple y única (186 A), brilla sobre todos (cf. Job 25, 3; Juan 1, 9). Hace levantar su sol sobre los buenos y los malos y caer la lluvia sobre los justos y los injustos (Mateo 5, 45). Calienta a todos con el calor de su bondad y los ilumina con el resplandor de la verdad (157 C-D). Luz eterna, inspira alegría a las conciencias rectas y remedio a las que están heridas (137 C).

Ese Padre de las luces, tan bueno y generoso para con todos, es el que ha enviado a su hijo único, que es luz de luz (Símbolo de Nicea) para iluminar las tinieblas de los mortales (59 A).

\section{EL HIJO}

El Hijo del Padre, que nació en la carne y dio vagidos en la tierra (52 A), es Dios, pero Dios vaciado de sí mismo. Recostado en un pesebre, no es más que un niñito, pero ese infante es el que rellena el cielo y la tierra (cf. Jeremías 23,24 ) y su majestad no cabe en la inmensidad del cielo. Está revestido de la gloria y del esplendor de la luz inaccesible y, como en un manto, se envuelve en esa luz sin límites (cf. Salmo 103, 1-2) (3) (36 B). Es niño, pero crea en los cielos un astro

(3) La numeración de los salmos corresponde a la versión de los LXX. 
nuevo para que una luz dé testimonio de la luz, para que una estrella dé testimonio del sol (52 A).

A pesar de ser luz de luz, había quedado escondido y desconocido hasta que dignó revelarse al mundo para la iluminación de todas las naciones $(51 \mathrm{~A})$, primero a los judíos por el testimonio de Juan el Bautista, en seguida en su bautismo en el Jordán con el testimonio del Padre y del Espíritu Santo y luego en las bodas de Caná con el cambio del agua en vino $(51 \mathrm{~B})$. Luz por excelencia, no soportó quedar ignorado y dio también testimonio de sí mismo afirmando: "Yo soy la luz del mundo" (Juan 8, 12-18) (177 A).

Él es Jesús el Cristo, nuestra luz verdadera, que ilumina a todo hombre que vive en este mundo (Juan 1,9) y que para eso vino a vivir entre nosotros como hombre: es la luz encarnada, que ha sido hecha lámpara para iluminar Jerusalén. Su encarnación tenía también como efecto que su palabra, que es la Palabra de Dios, se hiciera lámpara para nuestros pies (cf. Salmo 118, 105 (55 A). Iluminador de todas las naciones, vino en particular para iluminar los ojos de sus siervos, como lo recuerdan las antífonas de los domingos 1 y 2 del tiempo de Adviento. Esa iluminación inicia el juicio anunciado en Juan 9,39 (56 A - C).

Es el mismo niño, la fuente de la luz, que brillaba en las manos del anciano Simeón (Lucas 2, 28-32). A aquellos que se acerquen a él, les iluminará su fe, hará brillar sus buenas obras, les comunicará palabras de bien, encenderá sus oraciones, purificará sus intenciones de tal manera que, sea en la acción, sea en la conversación o en la oración, ellos buscarán cómo agradar a quien deberá examinar su luz. A quienes quieren caminar a su luz (cf. Isaías 2,5) les iluminará sus pasos y ellos en su luz verán la luz (Salmo 35, 10), esa luz que hace visibles las demás cosas (177 A).

Ese niño es el Cordero del Apocalipsis $(21,23)$, la lámpara de la nueva Jerusalén, la luz eterna anunciada por el profeta Isaías $(60,19)(67$ A-C).

Guerrico no se cansa de repetir que ese Salvador vino para todos y para cada uno en particular $(69$ C) y que él es esplendor $(178$ D). Esté humillado en su paso histórico por la tierra o esté en su estado glorioso actual, en su rostro siempre brilla la sabiduría. Y su rostro mismo es la irradiación de la luz eterna (cf. Sabiduría 7, 26). Para Guerrico, el rostro de Cristo es el reflejo de la luz que está escondida en su corazón. Ha sido y es un rostro siempre apacible, sereno e iluminado, tanto en los momentos de tristeza como en las alegrías. Guerrico le pide que su luz brille sobre los creyentes (cf. Salmo 4,7) y lo describe sonriente y agradable para los justos, clemente y afectuoso para los penitentes (137 B).

Así es el Hijo del Padre, el Verbo que se encarnó en el seno de María (118 A): es luz de eterno resplandor. Resucitado, es la luz de la mañana, aurora que no deja de renovar el misterio de resurrección (149 D - 150 A). Es la luz del mundo: luz en razón de su divinidad y candelabro en razón de su humanidad. Guerrico se refiere aquí al candelabro todo de oro de la quinta visión del profeta Zacarías (4, 1-14). Cristo es ese candelabro y es de oro macizo, el oro simbolizando o la divinidad o la sabiduría o la caridad, lo que Cristo es substancialmente (177 A-B). 


\section{EL ESPÍRITU SANTO}

Dios siendo padre de las luces y el Hijo, luz de luz, nada extraño que el Espíritu Santo también sea luz (cf. 157 D). Él es el eterno Espíritu que ilumina la fe $(113 \mathrm{C})$. Iluminó plenamente a María durante su vida terrenal y más ahora en el cielo (199 B), donde se está en plena luz, ya que la luz y la vida están en el cielo (186 D).

Invisible, quiso ser visto por los Apóstoles en el día de Pentecostés y se hizo visible como fuego, que inflamó e iluminó los corazones (179 B). Su acción continúa. Es esplendor que no se ve, pero con su gracia ilumina los intelectos, porque es la Verdad. Descubre los misterios y enseña la ciencia para que seamos prudentes como serpientes (cf. Mateo 10,16), para que tengamos la sal de la sabiduría que nos da la prudencia junto con la madurez. Su verdad sazona nuestra dulzura al mismo tiempo que él unge nuestros corazones $(178 \mathrm{D})$.

Guerrico no se explaya sobre el papel del Espíritu Santo en cuanto luz, pero destaca la importancia de su acción en el alma, que llena de esplendores. Cuando contemplamos la gloria del Señor es él que nos transforma en la imagen de Dios, de claridad en claridad (cf. $2^{a}$ Corintios 3, 18) (185 D).

\section{LOS MAGOS}

En su Sermo secundus de Epiphania, Guerrico se interesa por los magos, esos sabios de oriente que, según Mateo $(2,2)$, habían visto la estrella del rey de los judíos y habían venido a adorarlo. Esa estrella matutina indicaba el nacimiento del astro sin ocaso (Exultet). Era la auténtica estrella de la mañana que salió de Jacob (Números 24, 17). Ella había brillado en los corazones de los magos para darles la fe al mismo tiempo que hacía brillar exteriormente la estrella que los guió (Mateo 2, 9).

Guerrico hace un paralelismo entre ese episodio evangélico y un texto de Proverbios: "El sendero de los justos es como una luz resplandeciente que progresa y crece hasta el pleno día" $(4,18)$. El abad de Igny comenta que, en efecto, los magos primero entraron en el sendero de la justicia a la luz del astro resplandeciente; después, bajo su conducta, progresaron hasta ver el nuevo amanecer de la luz de la mañana y así, finalmente, llegaron a la contemplación de la faz del sol del mediodía en todo su esplendor.

Este paralelismo simbológico suscita otro en la mente del exegeta medieval. Los magos son las premisas de las naciones y los comienzos de la Iglesia naciente. La narración de Mateo es un primer anuncio, hermoso y muy significativo, del progreso de la fe en cada alma: de dónde parte, cómo se desarrolla y adónde, finalmente, llega.

El itinerario de los padres se reconoce en los hijos y es fácil verlo. Igual como los magos empezaron con la visión del astro, progresaron hasta la visión del niño y llegaron a ver a Dios, así en nosotros la fe nace de la predicación de las luminarias eternas - los apóstoles- y se fortalece con la visión de ciertas imágenes -los santosque nos muestran "per speculum et aegnimate" $\left(1^{a}\right.$ Corintios 13,12$)$ como a Dios 
encarnado. Esta fe nuestra se consumará cuando la verdad presente y sin velo de las cosas será vista por aquellos que contemplarán "facie ad faciem" (Ibid.). En la actualidad, esto se logra solo en enigma, muy débilmente y en forma fugitiva, pero, después, la fe se cambiará en conocimiento, la esperanza en posesión y el deseo en fruición (52 D-53 B).

Los magos, cuya iluminación ha inaugurado nuestra fe (59 b), fueron guiados por la fe y por la estrella. Nuestra estrella es la fe que nos conduce, como lo hizo con los magos, hacia nuestro jefe nacido en Belén (52 C).

\section{LOS SANTOS DEL CIELO}

La fe es nuestra estrella, pero, además, hay otras estrellas que brillan también para nosotros, no una sola como en el caso de los magos, sino muchas, aunque se podría decir que todas ellas son como una sola, porque tienen un solo corazón y una sola alma (cf. Hechos 4, 32), tienen la misma fe, una predicación concordante y una vida parecida.

El profeta Daniel nos señala quienes son esas estrellas cuando dice: "Los que enseñan la justicia a un gran número brillarán como estrellas en las eternidades sin fin" (12, 3). San Pablo llama "luminarias" a los que brillan en medio de una nación corrompida y perversa (Filipenses 2, 15). Esas luminarias llevaron en sí la palabra de vida como un resplandor de la luz eterna, gracias a lo cual han iluminado la noche de este mundo, como la luna y las estrellas rigen la noche (Salmo 135, 9). El mismo Señor dijo a sus discípulos: "Vosotros sois la luz del mundo" (Mateo 5, 14) y les encomendó que su luz brillara entre los hombres, para que ellos vieran sus buenas obras y glorificaran al Padre que está en los cielos (Mateo 5, 16). Ellos, de hecho, resplandecieron por la palabra y el ejemplo, anunciando así el amanecer de la luz eterna. Por la semejanza de su vida con la vida celestial, recomendaron la luz eterna, que de viva voz predicaban (53 B-D). Vivieron como ciudadanos del cielo (cf. Filipenses 3, 20). Astros destellantes, personas esplendorosas, su fe debe ser imitada y su santidad emulada. Refulgentes como llamas, nos señalan el amanecer de la luz de las luces; nos conducen a la cuna del nuevo rey, al impenetrable misterio de la fe; nos introducen en el templo real, en el santuario de Dios Padre, recompensa suprema de la fe.

De esas estrellas, algunas brillaron con una claridad admirable antes del orto del sol verdadero. Entre todas, emerge el hombre que vino como una antorcha a dar testimonio de la luz (cf. Juan 1, 7) (51 D), Juan Bautista, "el más grande entre los hombres" (Mateo 11,11), la estrella de la mañana la más resplandeciente. Fue la lámpara "ardiente y luminosa" (Juan 5,35) que el Padre preparó para su Cristo, fue el preludio de la luz, el precursor del sol y anunció a los mortales el día inminente de la llegada del reino de los cielos (Mateo 3, 2), como si hubiera dicho: "La noche está a punto de terminar y el día se acerca: rechacen las obras de las tinieblas (Romanos 13,12); despierta, levántate, tú que duermes, surge de entre los muertos y Cristo te iluminará" (Efesios 5, 14) (170 C-D).

En forma unánime, Marcos, Lucas y Juan dieron a Juan Bautista sus títulos de gloria desde el comienzo de sus evangelios, basándose en el hecho de que él es la 
lámpara del mundo, colocada en el vestíbulo de entrada para dar a conocer la luz verdadera (166 A), para conducir a la luz que brilla en las tinieblas, pero que las tinieblas no pudieron comprender (Juan 1,5) (171 A).

Otro santo, que también fue una lámpara ardiente y luminosa que dio testimonio de la luz, es el beato anciano Simeón (cf. Lucas 2, 25-35). Con gozo pudo llevar a Cristo en sus manos (63 B-C). Había llegado al Templo conducido por el Espíritu Santo del cual estaba lleno, para manifestar que Jesús, el Verbo presente en la carne, era la misericordia de su pueblo y la luz destinada a la iluminación de las naciones. Ese anciano sereno portaba la luz no solamente en sus manos, sino en sus sentidos. Estaba tan iluminado que veía claramente cómo la claridad de nuestra fe brillaba ya en medio de las tinieblas de su tiempo y, muy de antemano, vislumbraba la futura iluminación de los pueblos. Tenía oculto en su seno la gloria de la luz, pero ella calentaba sus sentidos. Ahora, en el cielo, contempla, alegre, cómo las tinieblas del mundo se han disipado y cómo la tierra se está repletando de la gloria de la luz que él ya había recibido (64 C - 65 A).

Ahora bien, nosotros no somos capaces todavía de contemplar la majestad divina: debemos contentarnos con admirar la claridad de los santos e imitar su santidad (53 D - 54 A). Es por la observancia de los mandamientos como nos iremos acostumbrando a los rayos de la luz hasta que más adelante podremos, con nuestros ojos, contemplar el foco mismo de la luz. Mientras tanto, no podemos contemplar el sol, pero nos es posible soportar la claridad de las estrellas y gracias a ella algún día tendremos la capacidad de mirarle a él (53 D - 54 B).

Mirar las estrellas del cielo desde las tinieblas es como mirar hacia las colinas de donde vendrá el auxilio (Salmo 120,1$)$, ya que la luz inaccesible ( $1^{a}$ Timoteo 6 , 16) resplandece maravillosamente desde esos montes eternos. Ellos han recibido la luz para el pueblo (cf. Salmo 71,3) y, de allí, ella baja en los valles y en las llanuras que están a sus pies.

Así, para nosotros, fijar la mirada en aquellos que ya han sido iluminados es una iniciación a la iluminación, excelente y adaptada a nuestra debilidad.

Los que siguen la luz de los padres que nos preceden toman la vía más recta para encontrar a Jesús. Seguir al justo es tomar un sendero recto (Isaías 26, 7) y luminoso. No solamente es no caminar en las tinieblas, sino que es tener ya la luz de la vida (cf. Juan 8,12) y el tener es mejor que el solo ver. Seguir el camino recto tiene su consuelo: poder desde ya ver la luz de la vida con la certeza de tenerla después en la posesión de la herencia eterna. A los que se aplican a las obras de la luz, el mismo Cristo Jesús, que vive y reina por todos los siglos de los siglos, se la muestra de vez en cuando para fortalecimiento y consuelo, antes de dársela en premio para siempre (54 B-C). A Pablo ese día de la luz eterna se le manifestaba a menudo, acota Guerrico (cf. $2^{a}$ Corintios 12, 1-7) (182 D - 183 A).

\section{LA IGLESIA}

A partir del texto de Isaías repetido en el oficio de la Epifanía “¡Levántate, resplandece, Jerusalén, porque ha llegado tu luz!" $(60,1)$, Guerrico ve en la ciudad santa la figura de la Iglesia (51 b). 
A diferencia de los pueblos que están en las tinieblas y optaron por ellas cuando la luz vino al mundo, la ciudad celestial está destinada a ser fecunda. A condición que ilumine, Jerusalén dará a luz para Dios hijos de todos los países y de todas las razas, hijos que la luz verdadera hará pasar del poder de las tinieblas al reino de su claridad (52 B).

Jerusalén, la Iglesia, nuestra madre, está iluminada y es madre de todos los que han merecido ser iluminados, de tal manera que ella ya ilumina a todos los que están en el mundo. Ella ha sido hecha lámpara para alumbrar a todos los que están en la casa del Padre (cf. Mateo 5, 15). Iluminada ella misma, ha sido puesta sobre un candelabro todo de oro como el del arca de la alianza (Éxodo 25, 31); es la ciudad colocada sobre el monte de los montes (Isaías 2, 2; Miqueas 4, 1) para que su evangelio brille en todas las direcciones del imperio del mundo. Si, antes, ella estaba abandonada y habitada por el odio, ahora ella es el orgullo de los siglos (Isaías 60, 15) (55 A-B). Su resplandor destella para que se pongan envidiosos aquellos para quienes el evangelio está escondido. Su gloria atormenta a los que no quieren ser iluminados por la gracia. Pero esa misma Iglesia, que brilla de la gloria de Cristo, no se pone soberbia, aunque la gloria la hace florecer, ni se vuelve celosa respecto de la gracia que hace su fuerza. Al contrario, ella implora la misma luz que ella ha recibido para aquellos perseguidores que ella soporta.

Guerrico declara hijos de la Iglesia a todos los predestinados. Aquellos predestinados que son ciegos y no ven el evangelio, son infieles y se están perdiendo: su mente ha sido cegada por el dios de este mundo $\left(2^{a}\right.$ Corintios $\left.4,3-4\right)$, pero son de la Iglesia. Todavía no han sido llamados ni justificados (cf. Romanos 8, 30), por eso son tinieblas. La Iglesia los llama "mis tinieblas" y ruega por ellos con las palabras del salmista: "Ya que iluminas mi lámpara, Señor Dios mío, ilumina mis tinieblas" (cf. Salmo 17, 29) y sigue su petición: "Llámalos ellos también a tu luz admirable (cf. $1^{a}$ Pedro 2,9$)$ y conmigo proclamarán tu Nombre admirable" (55 B-C).

\section{LOS HIJOS DE LA LUZ}

Entre los hijos de la Iglesia aquellos que son justos y santos se alegran de haber sido iluminados, pero son lúcidos: ven la no pequeña parte de tinieblas que hay en ellos y esto les duele. Han sido iluminados, pero piden serlo de nuevo. Cuanto más su lámpara ha sido iluminada, en esa misma medida perciben la verdad de sus tinieblas. Con la sinceridad de la intención, la acción puede ser luminosa, pero esto no significa que todas las tinieblas de los errores e ignorancias estén iluminadas. Los que más han progresado en la luz de la verdad son aquellos que han podido conocer sus defectos y saber lo que les faltaba. Y Guerrico apela aquí a los filósofos antiguos, discípulos de Sócrates (4), que afirman que el primer grado de la ciencia es saber que uno no sabe.

Los hijos de la luz son hijos del día, no de la noche ni de las tinieblas (Cf. $1^{a}$ Tesalonicenses 5, 5). La noche ya pasó y el día ha llegado (cf. Romanos 13, 12).

(4) Cf. PlATÓN, Apología de Sócrates, 23 b. 
Aquellos que alguna vez fueron tinieblas, ahora son luz en el Señor (Efesios 5, 8), sin embargo sufren algo de las tinieblas y no lo pueden negar sin engañarse e introducir en sí mismos las tinieblas de la muerte.

Con el salmista, Guerrico reconoce que el Señor ha iluminado la lámpara de los justos, lo que les permite ver un poco, pero es tan poco lo que ven que tienen que pedir al Señor que ilumine sus tinieblas (cf. Salmo 17, 29). En efecto, a lo más ven "como en un espejo y en enigma" ( $1^{a}$ Corintios 13,12$)$, pero esto mismo está muy lejos de la verdadera claridad y de la clara verdad que se verá cara a cara. Quizá por eso, añade Guerrico, el ciego, que el Señor había empezado a iluminar, veía hombres como árboles caminando, pero después, al imponerle de nuevo las manos, Jesús lo restableció de tal manera que vio claramente todo (Marcos 8, 2225). Esto es lo que pasará con los justos cuando, por la segunda imposición de las manos, Él rehará y perfeccionará la salud empezada por la primera imposición, restableciendo así a los hijos del día en la claridad perfecta (55 D - 56 B).

Ver "per speculum et aenigmate" es una gracia que Dios concede en su misericordia. Ahora bien no todos son iluminados suficientemente para darse cuenta de sus pecados. El salmista lo dice: "Innumerables males me rodean y no he sido capaz de verlos” (Salmo 39, 13), “QQuién entiende sus pecados?” (Salmo 18, 13). El vicio engaña y mata bajo la apariencia de la virtud como un ángel de las tinieblas disfrazado en ángel de luz (5). Es un gran santo y un hombre muy bien iluminado aquel que ha podido y ha querido comprender claramente sus delitos, cosa que el Artero mismo no ha podido ni ha querido entender.

La iluminación de los justos, su lámpara, es su fe y la luz que ella proyecta. Esa luz de la fe es el primer grado en la progresión hacia la patria de la claridad. El justo se alegra de haberla recibido, pero anhela la iluminación de las tinieblas que han quedado en él, aspira a la luz de la justicia, a la luz de la ciencia y a la luz de la sabiduría (56 B-D).

\section{EL RECORRIDO DEL ALMA FIEL}

La vida actual de los creyentes se desarrolla entre los dos advenimientos corporales del Hijo: su nacimiento en la carne y su llegada al final de los tiempos. Los fieles, sin embargo, no están sin ver, porque existe un advenimiento espiritual, admirable, pero escondido, que llega en forma secreta y que, sin que se vea su llegada ni su partida, ilumina el alma y el intelecto con una luz que les hace ver lo invisible y conocer lo incognoscible (16 D - $17 \mathrm{~A})$.

No basta que el alma haya progresado en la vía del Señor hasta poseer una voluntad recta y costumbres sosegadas (25 A); ella debe progresar para que, liberada de las tinieblas de este mundo, llegue a la patria de la claridad eterna, donde las tinieblas son mediodía y la noche, día (cf. Salmo 138, 12); allá, ella verá y estará en la abundancia y su corazón se maravillará y se dilatará, cuando toda la tierra estará

(5) Ver la misma idea cuatro siglos más tarde en S. IGNACIO DE LOYOLA, Ejercicios espirituales, $\mathrm{N}^{\circ}$ 332: "Propio es del ángel malo, que se forma sub angelo lucis, entrar con la ánima devota y salir consigo". 
repleta de la majestad de la luz infinita y su gloria se verá en el alma misma (cf. Isaías 60, 2) (56 D).

\section{LOS TRES GRADOS}

La vía por la cual el alma fiel debe progresar consta de tres grados. A cada uno corresponde una luz: la luz de la fe, la luz de la justicia y la luz de la ciencia, último paso de la progresión hacia la luz de la sabiduría.

Los hijos de la casa de Jacob están invitados a caminar en la luz del Señor (cf. Isaías 2, 5) para que, como hijos de la luz (cf. Efesios 5, 8), progresen de claridad en claridad bajo la guía del Espíritu $\left(2^{a}\right.$ Corintios 3,18$)$ y avanzando por cada grado de las virtudes se adentren más en el reino del esplendor. Por la fe, ya están en la luz. A partir de ella y gracias a ella van avanzando hacia la luz más amplia y más serena de la justicia. Lo que creen por la fe, lo deben cumplir y merecer por la justicia; por la ciencia lo comprenderían y por la sabiduría lo contemplarán.

Guerrico explica que la lámpara de la fe ha sido prendida para que actuemos a su luz en la noche de este siglo. Por eso está escrito en alabanza de la muerte fuerte, quien se levanta de noche y trabaja con sus manos de noche y de día y no come su pan en la ociosidad, que "su lámpara no se apagará de noche" (Proverbios 31, 15 27), lo que significa que su fe no desfallecerá en la tentación (66 A).

Las obras de las tinieblas, cuando se realizan, apagan la luz de la fe. En efecto, el que actúa mal odia la luz (Juan 3, 20). Él apaga la lámpara de la fe y deja de lado el recuerdo de Dios. El temor de Dios no está ante sus ojos (Salmo 35, 2). Se felicita de las tinieblas que se ha creado y de la ausencia de testigos. Dice: “¿Quién me ve? Las tinieblas me rodean y las paredes me cubren. Nadie me mira. ¿A quién temeré? El Altísimo no se acordará de mis faltas". No entiende que el ojo de Dios lo ve todo (Eclesiástico 23, 18-19).

En cuanto a las obras de la luz, las buenas obras, ellas son lámparas ardientes en las manos de aquellos que las realizan en la espera de la llegada del Esposo. Aunque a veces uno las realiza en secreto para evitar la vanidad, ellas se cumplen sin embargo en la luz, la luz de la justicia, la cual es una luz doble: la luz interior y la luz eterna, la luz del juicio de la fe propia y la luz del testimonio de Dios. Esa justicia, que consiste en las buenas obras, en la bondad y en la disciplina, Dios la hará brillar como una luz (cf. Salmo 36,6) ante los hombres y ante los ángeles. Resplandecerá como la luz del mediodía, porque sus obras son hechas en Dios, y brillará de tal manera que los juicios de todos glorificarán a Dios en el alma fiel y a ella en Dios (56 D- 57 C).

La luz de la justicia alegra la conciencia del justo. Ocurre a menudo, sin embargo, que la fe irradie y que la justicia corusque, pero que el intelecto esté todavía en la tiniebla. En estos casos, el intelecto venera el misterio de la fe $\left(1^{a}\right.$ Timoteo 3,9), pero no lo sabe explicar. El libro de la Escritura le está sellado, como si no supiera leer. No tiene los sentidos ejercitados para discernir el bien del mal (cf. Hebreos 5, 14) ni lo verdadero de lo falso. Hay muchos así en la Iglesia, que tienen mucha fe, cuya justicia es abundante, pero cuyos conocimientos son casi nulos. Esto no parece inquietar demasiado al sabio tornacense, quien recuerda una enseñanza 
del profeta Oseas $(10,12$, en la versión de los LXX): el mérito y el ejercicio de la justicia encienden la luz de la ciencia (57 C- D). Guerrico precisa que esa luz de la ciencia espiritual la enciende la lectura frecuente, pero no en cualquier caso, solo si cuando se lee se usa una lámpara ardiente, a saber aquella de la justicia de las obras unida a la experiencia de los sentidos espirituales (58 D).

La luz de la sabiduría, meta final del recorrido por los tres pasos de la fe, la justicia y la ciencia, la enciende la oración ferviente $(58 \mathrm{D})$, pero es de un orden superior, donde el Espíritu Santo interviene de una manera especial. Guerrico define la sabiduría. Es más que una simple iluminación del intelecto, es el sabor y el gusto de las realidades eternas. Consiste en ver y gustar cuán dulce es el Señor (Salmo 33, 9), cuando el Espíritu Santo revela lo que el ojo no ha visto ni el oído escuchado y que nunca ha subido al corazón del hombre (cf. $1^{a}$ Corintios 2, 9-10). Se trata de una iluminación magnífica y gloriosa gracias a la cual el alma contempla la gloria del Señor (cf. $2^{a}$ Corintios 3,18 ). A la persona así favorecida ya no le habla un profeta, sino el Espíritu de los profetas cuando dice: "Levántate, resplandece, Jerusalén, porque ha llegado tu luz y la gloria del Señor se ha levantado sobre ti" (Isaías 60, 1) (58 C-D).

Estos tres grados y la luz de la sabiduría conforman la vía de las luces por la cual se llega a la luz eterna, la luz de los vivientes (cf. Salmo 55, 14) en la que seremos agradables al Padre de las luces (59 A). Para caminar con un paso firme por esa vía, es necesario tener la cintura bien ceñida y sostener en las manos lámparas ardientes (Lucas 12,35), hay que ser ardientes en devoción y radiantes en obras, hay que imitar a Simeón y llevar a Cristo en las manos (cf. Lucas 2, 28) (63 b-C). Hay que llevar lámparas y hay que ser lámparas.

\section{EL TEMA DE LAS LÁMPARAS}

El tema bíblico de la lámpara ("lucerna") ha sido explotado por Guerrico en forma sistemática.

Cristo, la luz verdadera, ha sido hecho lámpara para iluminar Jerusalén (55 A), el Cordero es la lámpara de la nueva Jerusalén (Apocalipsis 21, 23) (67 C), Juan Bautista fue una lámpara excepcional (cf. Juan 5, 35) (51 D, 170 C, 171 A), el anciano Simeón también (64 D).

La palabra del Señor es lámpara que ilumina los pasos (Salmo 118, 105) $(25 \mathrm{~A})$, su mandato es una lámpara (Proverbios 6, 23) (25 A), que ilumina los ojos (Salmo 18, 9) $(54 \mathrm{~A})$. La fe es nuestra lámpara (56 C) y las obras de la luz son lámparas ardientes (57 C), sin olvidar que el ojo es la lámpara el cuerpo (Mateo 6, 22) (55 C).

A la luz de todas esas lucernas, el abad de Igny exhorta a sus hermanos para que ellos mismos sean lámparas. Para cumplir la orden del Señor, tienen que acercarse a Él para ser iluminados (cf. Salmo 33, 6), de tal manera que, siendo ellos mismos lámparas, iluminen por dentro y por fuera, proyectando su luz para sí mismos y para el prójimo. Cada uno debería tener tres lámparas, una que brille en el corazón, una segunda en la mano y otra en la boca. La del corazón, que es la "pietas" de la fe, es para iluminar el alma misma. Las otras dos son para el prójimo: aquella de la mano es el ejemplo de las buenas obras, la de la boca es la palabra que edifica. 
Pero brillar ante los hombres por la acción y la palabra no es suficiente. Hay que ser lámpara ante los ángeles por la oración y lámpara ante Dios por la intención. La primera consiste en la pureza de la devoción, en la salmodia bien cantada (cf. Salmos 46, 8), en la oración ardiente. La segunda es la simplicidad de la intención de agradar al único Dios (cf. $1^{a}$ Timoteo 2, 5). (65 C-D, 66 A).

Una vez encendidas todas esas lámparas, los hermanos, hijos de la luz, no caminarán más en las tinieblas y no tendrán ningún motivo de temer que su lámpara se apague en medio de las tinieblas, no serán sumergidos por todos lados por las tinieblas de afuera y de dentro, no serán despojados del consuelo de esa luz. Por lo contrario, si bien caminen entre las tinieblas, la fe iluminará sus ojos y dirigirá sus pasos de tal manera que contemplarán las realidades invisibles y meditarán su futura bienaventuranza ya poseída en el espíritu (78 A).

Para aquellos que poseen interiormente tantas lámparas ardiendo, cuando se apague la lámpara de esta vida, se levantará la luz fulgurante de la vida inextinguible. En lugar del fin temido, ellos se levantarán como la estrella de la mañana y sus tinieblas serán como el mediodía (Job 11, 17; Isaías 58, 10). Sin embargo, para ellos ya no habrá ni sol ni luna, sino que el Señor será su luz permanente (Isaías 60, 19, Apocalipsis 21, 23) (67 A-C).

\section{BIBLIA Y TRADICIÓN}

Previniendo que sus afirmaciones podrían ser tildadas de simples frutos de la imaginación, Guerrico explica que todo lo que ha expuesto está conforme a los testimonios de la Escritura y aporta sus referencias.

$\mathrm{Fe}$, caridad, acción buena, palabra edificante, palabra profética, explicación de las palabras divinas, oración, intención son otras tantas lámparas para las cuales Guerrico trae textos bíblicos justificativos, algunos de ellos tomados en el sentido literal, varios interpretados a partir de una exégesis espiritual que ofrece toda la gama de los sentidos alegóricos, tropológicos y anagógicos.

En esto es plenamente de su tiempo. Inspirado directamente en la Biblia, la luz cósmica, que aparece ya en Génesis 1,3-4, le sirve para hablar de la luz divina, de la luz mesiánica, de la luz escatológica y de la luz de la sabiduría. El centro de su teología es Jesucristo, la luz verdadera (Juan 1,9), luz que se comunica y es palabra, vida, verdad, caridad, salvación, testimonio y juicio.

Su conocimiento de la tradición patrística lo ha puesto en contacto con las ideas de sus predecesores respecto de la iluminación. Sin embargo, no parece depender de ninguno en particular.

\section{PARA CONCLUIR}

Guerrico de Igny es un abad culto que escribió sus sermones para una comunidad concreta. No se pierde en disquisiciones. Es un espiritual realista que constata que el monje es un "homo viator" en el cual queda siempre algo de tinieblas y cuya iluminación se realiza paulatinamente. Los hijos de la luz avanzan por etapas, gozan 
a veces de momentos privilegiados de una contemplación más elevada, pero es poco a poco que se van transformando, de claridad en claridad, en una más perfecta imagen de Dios.

La teología del beato Guerrico es la de un sabio, que fue él también y sigue siendo para aquellos que lo leen, "una lámpara ardiente y luminosa".

\title{
RESUMEN
}

El beato Guerrico de Igny nos ha dejado 54 sermones. Uno de los temas recurrentes de su doctrina espiritual es el de la luz, que proviene del Padre Celestial, se encarna en Jesucristo, ardió en esas lámparas llamadas Juan Bautista, los magos y Simeón, y sigue iluminando toda la historia de la salvación, brillando en las diferentes acciones de sus actuales discípulos.

Pensador original, el célebre abad cisterciense enriquece con sus aportes personales una teología de la luz que se encontraba ya esbozada en Orígenes, Agustín, el Pseudo Dionisio, Casiano y Bernardo.

\begin{abstract}
Blessed Guerrico de Igny has left us 54 sermons. One of the recurring themes of his spiritual doctrine is that of light, which proceeds from the Celestial Father, is incarnated in Jesus Christ, burned in those luminous figures called John the Baptist, the astrologers and Simon, and continues to brighten all of salvation history, shining in the different actions of his current disciples. An original thinker, the celebrated Cistercian abbot enriches with his personal contributions a theology of light that was already found outlined in Origen, Augustine, PseudoDionysius, Cassian and Bernard.
\end{abstract}

